\title{
Curriculum design
}

\author{
Stella Lowry
}

This is the third in a series of articles examining the problems in medical education and their possible solutions.
In 1991 the General Medical Council issued a consultation document about the need for reforms in the undergraduate medical curriculum.' The council expressed concern at the response of many students to the present course- "it is distressing to see the progressive disenchantment of many of them as they work their way through the course. Imagination and curiosity are soon dulled ..."- and highlighted the overburdened curriculum, with undue emphasis on the passive acquisition of facts that were soon forgotten, as a major area for reform. Instead, the council wants more promotion of self learning skills and cultivation of the attitudes needed to keep up to date with a rapidly changing subject like medicine.

The council defined the primary aim of the undergraduate course in terms of acquiring "an understanding of health and disease, and of the prevention and management of the latter, in the context of the whole individual in his or her place in the family and society." To this end it set out some essential components of the course (box A).

It defined the second aim of the course as developing "an attitude to learning that is based on curiosity and the exploration of knowledge" and stated its intention to "reduce the excessive burden of information in the existing undergraduate course." The council recommends that schools should substantially reduce the amount of face to face teaching that goes on and instead offer support and guidance for students to direct their own learning. Other recommendations include a clinical component from day 1 and the need to acquire an understanding of scientific method.

The most striking feature of the new proposals is the introduction of the concept of a "core" curriculum and "options." The core, which might vary slightly from

\begin{tabular}{l} 
Box A \\
Features that GMC considers to be essential \\
aspects of undergraduate curriculum \\
- Knowledge and understanding of scientific basis \\
of medicine \\
- Introduction to range of problems presenting to \\
doctors and range of possible solutions \\
- Understanding of basic disease processes \\
- Ability to elicit history and perform physical \\
examination \\
- Understanding of mental illness and psycho- \\
logical responses to physical illness \\
- Appreciation of health promotion and disease \\
prevention \\
- Understanding of principles of therapy and \\
disease management \\
- Understanding of reproductive cycle \\
- Understanding of human relationships \\
- Understanding of organisation of health services \\
- Awareness of ethical and legal responsibilities of \\
doctors \\
- Skill in essential clinical procedures like cardio- \\
pulmonary resuscitation \\
- Development of capacity for self audit \\
\hline
\end{tabular}

school to school, would be required of all students, but the optional aspects would allow in depth study of some aspects which the students would largely select for themselves. Professor D Shaw, chairman of the GMC's education committee, now admits that the choice of the word "options" was unfortunate, as a major stumbling block in negotiations about the proposals has been the unwillingness of staff to admit that their subject does not have to be part of the core. Despite the semantic problems, however, the council is convinced that the educational objectives of the undergraduate curriculum can best be achieved by reducing the compulsory elements to not more than two thirds of the total course time. In fact, it is unlikely that the options would be a dumping ground for mino specialties. More probably they would develop as an opportunity for project work or electives, giving a deeper exploration of parts of the core curriculum that had particularly interested the student.

Because the council recognised that the proposed changes will mean considerable upheaval for many schools it decided to issue a consultation documen outlining its proposals. It accepted that full implementation would probably take 10 years. The counci has now received responses from the medical schools and other interested bodies and is deciding on the nex step.

\section{National consensus}

The GMC is not the only organisation looking at the current problems in British medical education. In 1990 the King's Fund Centre, in collaboration with $S$ Bartholomew's Medical School and City and Hackney Health Authority, London, set up a national inquiry into the subject, with the aim of establishing guidelines for redesigning the undergraduate curriculum. The inquiry used a modified Delphi technique to reach consensus through several rounds of consultation. In the first round participants were sent a series of propositions and questions on medical education and asked to suggest other topics that should be covered. In the second round a new list was circulated and participants asked to comment on that. In round 3 summary of the comments received after round 2 was circulated for additional comments and to allow participants to see the extent of consensus emerging The consultation ended with a conference in April 1991, from which written recommendations were issued. ${ }^{2}$ The inquiry confirmed that there is widespread agreement among medical teachers that the undergraduate course is overcrowded and inhibits students from critical and creative thinking. The key issues identified by the inquiry are summarised in box B.

Many of the identified aims of an ideal curriculum are in line with the GMC's recommendations, but the inquiry also looked at barriers to implementing change and how they might be overcome. Among factors likely to aid change the report identified the strong lead from the GMC, the introduction of university contracts and NHS job plans giving deans the opportunity to specify teaching commitments, and the opportunity to use the allocation of SIFTR (service increment for teaching

\section{London WC1H 9JR}

Stella Lowry, assistant editor 


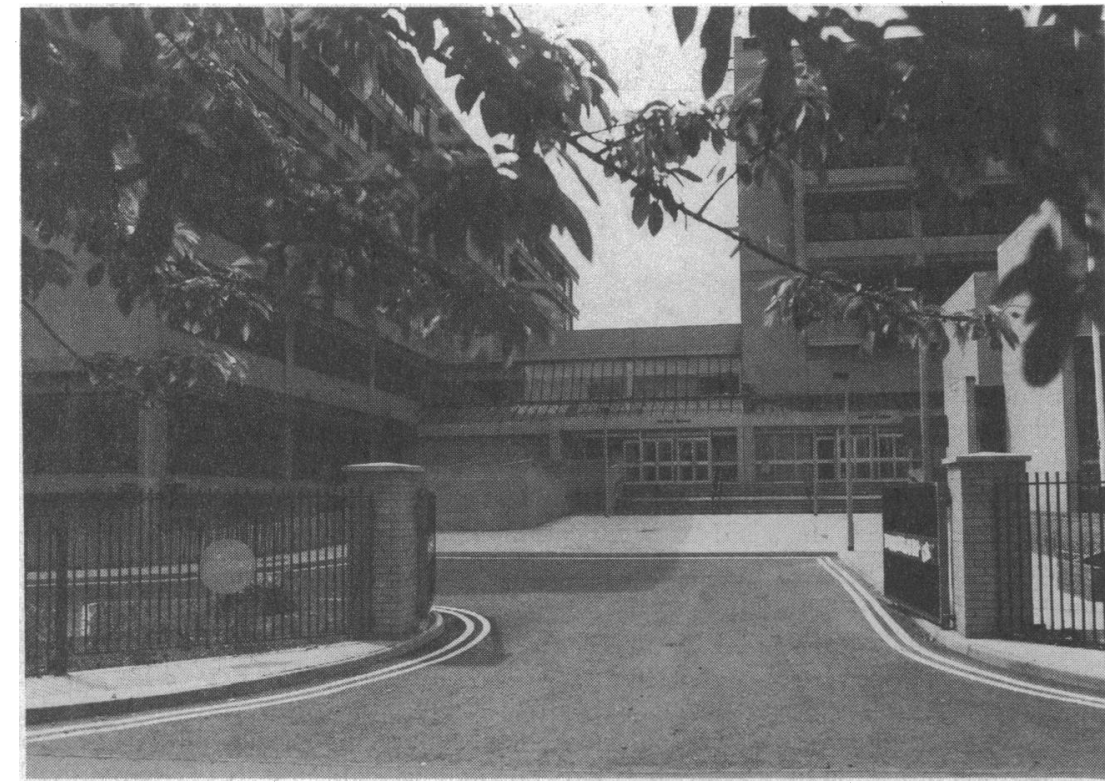

FIG 1-Newcastle medical school, which has engineered a series of major innovative changes in its curriculum since 1962

and research) money to add weight to these demands. The low status of teachers in medical education, the departmental organisation of many courses, and the traditional divide between the basic sciences and the clinical course were identified as major barriers to change.

The report also emphasised that many medica schools were already some way along the road to implementing desired change but that the absence of a national forum for the exchange of ideas and information meant that time was being wasted by individual units reinventing the wheel and failing to learn from other people's mistakes. Perhaps the most useful thing to come out of the King's Fund initiative has been the establishment of a national forum for the exchange of information about medical education initiatives (box $\mathrm{C}$ ).

\section{Unhappy staff, unhappy students}

St Bartholomew's Hospital Medical School was closely concerned with the King's Fund in setting up its inquiry into medical education, and it is one of the schools that has already made progress in implementing

\section{Box B}

Key issues in curriculum development identified by King's Fund inquiry

- Need to define core knowledge, skills, and attitudes in line with GMC's recommendations-possibly by setting up national advisory group

- Integration of preclinical and clinical teaching by redesigning curriculum as continuum

- Introduction of self directed learning

- Development of new methods of student assessment to test all desired knowledge, skills, and attitudes

- Proper recognition for medical teachers, with teaching commitments specified in contracts, audit of teaching quality, and appropriate financial rewards for teaching excellence

- Staff development to allow teachers to take on their new roles

- More teaching in outpatient clinics, general practice and community settings, and skills laboratories

- Proper management of change within medical schools, with appropriate funding and evaluation of process

\section{Box C}

"Change in Medical Education"

"Change in Medical Education" is a network of people interested in sharing information and ideas about the current problems and changes in medical education. I was set up by the King's Fund after publication of its inquiry into these issues, and members receive quarterly newsletter and invitations to conferences, workshops, and seminars. Anyone interested in joining should contact Dr Angela Towle at the King's Fund Centre, 126 Albert Street, London NW1 7NF.

changes in line with the GMC's proposals. The driving force behind these changes has been the dean, Professor Lesley Rees, who was horrified at the transformation of eager, bright school leavers into dull, demoralised doctors in five short years. She organised a series of surveys of students and recent graduates and confirmed that they thought the course was overcrowded and relied too heavily on the passive recall of facts and that the preclinical course had too little obvious clinical relevance. A survey of the teachers in the preclinical departments found that they too were unhappy. They were bored by what they had to teach and demoralised by the effects of the course on their pupils.

A curriculum steering group was convened. All the members had an interest in medical education, but no attempt was made to ensure that all departments were represented. The school has now introduced an innovative preclinical course, although the clinical years have yet to be tackled. Within the new course there is considerable integration of subjects, so that departmental boundaries are blurred, lectures are limited to a maximum of two a day, and there is a large element of community based education and teaching of communication skills. Although the first group of students to follow the new course did well, the examination results for the second year were disappointing (B Jolly, personal communication). The school is trying to identify why this happened, but preliminary comments from the students suggest that they were not all fully prepared for the responsibility of self directed learning - "Initially we didn't know how to begin and wasted many hours wondering where to find information." There is no point in introducing change unless all those concerned understand the processes.

\section{Change as a dynamic process}

Innovative attitudes to medical education are not new, even in Britain. Newcastle medical school (fig 1) has undergone a series of major innovative changes starting in 1962. Throughout, the aim has been to break down the traditional barriers between clinical and preclinical studies by teaching around the major systems of the body rather than along traditional departmental lines. ${ }^{3}$ The course has undergone three major revisions-in 1962, 1976, and 1988. The present course consists of modules of teaching based on the major organ systems. Each module is controlled by an interdisciplinary system course subcommittee of students and staff from the basic and clinical sciences, which reports eventually to the faculty teaching committee chaired by the dean.

Dr Reg Jordan, academic subdean of the Newcastle medical school, emphasises that effective curriculum development is an ongoing process: "Change is an ongoing dynamic process, with peaks and troughs." The subcommittees at Newcastle are constantly monitoring and refining the courses that they supervise, but on top of that there have been three major revisions of the overall policy. The first two were primarily 


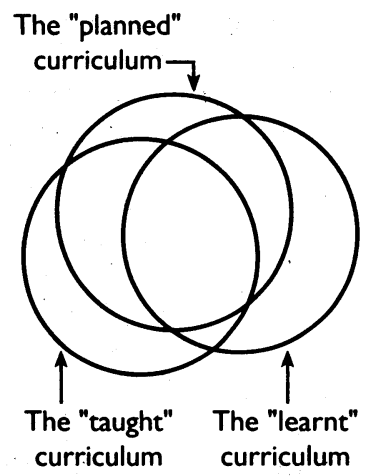

FIG 2-Three curricula model of any medical course concerned with integrating the basic sciences and clinical teaching. By the mid-1980s, however, it was apparent that the course was still overloaded, and the teaching committee was also concerned that students were not developing their self learning potential properly. The committee examined the factual content of the first year of the course and succeeded in redefining the core of factual information to be included. The formal, timetabled element of the course was thus reduced by a quarter, and about half of the total teaching time in the week is now available for private study. Dr Jordan thinks that as well as defining core knowledge clearly schools have a duty to "make a clear statement about what students do not need to learn" as this helps to reduce student anxiety in courses with a large element of self directed learning.

During the most recent reorganisation of the Newcastle curriculum the teaching committee also introduced a new system of student assessment in the hope of shifting the emphasis from rote learning of facts to the development of learning skills and deeper understanding of underlying principles. More emphasis is now placed on "open book" in course assessments by means of essays, longer dissertations, and practical projects. These are supplemented by more traditional multiple choice question papers, data interpretation and objective structured practical examinations, short answer papers, and essays.

The first group of students to complete the new course is due to graduate in 1992, so formal evaluation of the success of the approach is still limited. So far, however, feedback from the students has been encouraging, although some members of staff are still worried that there has been "change for change's sake." Dr Jordan emphasises that it is often impossible to prove that a particular way of teaching is "better" than any other but that it "feels more sensible to teach this way."
The developments at St Bartholomew's and Newcastle prove that if a few key members of staff are willing to make a stand the required factual content of the undergraduate medical course can be defined and reduced. This is encouraging, given the caution expressed by some respondents to the King's Fund inquiry. ${ }^{2}$ Nevertheless, it may still be more effective to set up a national advisory panel to define the core required of all students, as suggested in the King's Fund report, than to leave the brave to introduce change and the cautious to do nothing.

\section{The three curricula model}

It is not enough merely to define the teaching content of a course. What teachers teach and what students learn may not be the same. Dr Colin Coles, from Southampton, suggests that the education process can be illustrated by a three curricula model (fig 2). One curriculum is that which the faculty intends should be taught (the "planned" curriculum); another consists of what the teachers do, in fact, teach (the "taught" curriculum); and the third is what the students actually learn (the "learnt" curriculum). The degree of overlap among these curricula will vary, and any attempt to change a course needs to take account of all three aspects. Concentrating solely on what you plan to teach may have little impact on what students learn.

Many strategies have been adopted to try to implement desired change. Next week, I shall examine some of these and discuss their value in reforming medical curricula.

1 General Medical Council. Undergraduate medical education. The need for change. London: GMC, 1991

2 Towle A. Critical thinking: the future of undergraduate medical education. London: King's Fund Centre, 1991

3 Walton JN. On training tomorrow's doctors: the Newcastle curriculum revised and reconstructed. $B M \mathcal{1} 1977 ; \mathrm{i}: 1262-5$.

\title{
How To Do It
}

\section{Making an application for part time senior registrar training}

\author{
JE Morrell, A J Roberts
}

Part time training is a valuable career option for men and women, but it is taken up most frequently by women with young children. Two large surveys of doctors showed widespread support for part time posts, ${ }^{12}$ even though Warren and Wakefield found almost half their respondents believed part time training to be difficult either to organise or to undertake. ${ }^{2} \mathrm{~A}$ report by Isobel Allen, commissioned by the government in 1988, highlighted the second class image of part time workers. ${ }^{3}$ This problem also emerged in work with doctors conducted by Proctor, ${ }^{4}$ Roberts, ${ }^{4}$ and Gath, ${ }^{5}$ though they found the women they studied to be well qualified, motivated, and aiming for consultant posts.

The structure for setting up a part time training has operated in various forms for more than 20 years, ${ }^{\circ}$ although the first part time general surgical trainee has only just been appointed. The regulations are now known as PM(79), a reference to the original memorandum in 1979 from the then Department of Health and Social Security to regional health authorities and other relevant bodies. This summarises arrangements for the establishment of training posts for doctors and hospital dentists able to work only part time for reasons of domestic commitments, disability, or ill health. It requests health authorities to give every encouragement to such doctors and dentists to remain in the NHS. Here we will deal only with senior registrar training. A new simplified scheme for part time registrars has recently come into operation.

\section{How the scheme works}

Part time training opportunities are available in all specialties and there should be manpower control to ensure that it is neither easier nor harder to obtain a part time post than it is to train full time. There is competition between candidates and the same criteria are applied to part time and full time applicants.

The Department of Health advertises the scheme every year and receives quotas from the Central Manpower Committee on the number of posts to be allowed in each specialty. The numbers are collated quarterly; at present there are only 380 part time trainees in England and Wales.

The application procedure involves three steps: manpower approval, eductional approval, and funding.

There appears to be widespread ignorance about the scheme and a lack of preparedness for dealing with candidates that can cause great frustration. Below is set
Correspondence to:
Dr Morrell.

BMF 1992;305:1411-3 